\title{
THE NORMATIVE SOCIOLOGY OF PIERPAOLO DONATI: A POLEMICAL NOTE ON "THE POSSIBILITY OF HUMANISM AFTER MODERNITY: THE RELATIONAL PERSPECTIVE”
}

\author{
Michał Federowicz \\ Daniel Roland Sobota \\ Polish Academy of Sciences
}

The text by Donati entitled "The Possibility of Humanism After Modernity: The Relational Perspective" is not purely sociological in nature. ${ }^{1}$ It is rather located on the borderline between the disciplines, that is, between a strictly sociological approach to human nature, and philosophical interpretations. These interpretations, as social philosophy, philosophical anthropology, or ethics, not only venture to reflect directly on the essence of mankind and its exceptionality but also to place the answers in a larger metaphysical or ontological context. Therefore, in the first part of the present text, we will first consider some of the sociological problems that Donati's proposal faces. In the second part, we will scrutinize the broad philosophical context that the proposal attempts to oppose. Certainly, it should be borne in mind that the paper under review is only a minor part of Donati's enormous intellectual corpus, and merely hints or signals what is clarified and built upon in his work. For the sake of precision and methodological honesty, a thorough assessment of the concept of relational sociology as presented by Donati should then take into account the other

\footnotetext{
${ }^{1}$ The text presented at the seminar "Humanism in an After-Modern Society: The Relational Perspective," University of Warsaw, March 6, 2017, is an enlarged version of the chapter Transcending the Human: Why, Where, and How? by Pierpaolo Donati in Ismael Al-Amoudi and Jamie Morgan (eds.), Ex Machina: Realist Responses to Posthuman Society, Routledge, 2018.
} 
works in his corpus. Unfortunately, we cannot do justice to his body of works in the space available to us. Briefly, however, we can indicate a few issues which appear not only in the text under review but also in some of Donati's other texts and which raise more or less serious reservations.

Of course, it would be highly unjustified to contend that each sociological theory that aspires to be useful for the study of particular social phenomena should, as a point of departure, recognize the fundamental philosophical dilemmas that such a theory automatically presupposes. In truth, all major scientific revolutions are accompanied by subversions in the paradigms of our reasoning in the remaining domains of culture, including mainly philosophy. However, these two revolutions are to a large extent independent of one another. It is perhaps because the subject matter of sociology is situated on a totally different level of abstraction than the main topic of a purely philosophical theory. It would be in vain to expect a sociologist, before he embarks on his usual empirical investigations, to settle the current philosophical problems; in doing so, he or she would merely risk being entangled by those philosophical issues and not arriving at an empirically relevant theory at all. Nevertheless, it is also impossible to believe that by utterly ignoring these problems, he or she would avoid the risk of discovering what is already well known. Donati would definitely like to avoid both those dangers. Still, the fact that he sets high demands for his theory, both philosophically and sociologically, makes his theoretical proposal vulnerable to a two-fold danger: from a sociological vantage point, the danger is that it will become overly theoretical or ideological; and from the philosophical vantage point, that it will involve a resort to clichés and lack proper philosophical sophistication.

Let us first recall what is at stake here. Donati's purpose is to retrieve the possibility of humanism after modernism has revealed its dehumanizing face. First and foremost, the author strives for a theory that would be grounded upon a deeply humanistic understanding of the essence of the human being and his or her relations with Others. Hence, such a theory would allow people-unlike in the case of dehumanizing theories-to have better self-understanding and consequently, to fulfil their human potential. To attain these goals, Donati must avail himself of philosophical tools; but because he also wants his theory to be principally sociologicalthat is, to be applicable to empirical investigations and be useful for practical actions - it cannot be overburdened with philosophical speculations.

The text we are commenting on here entitles and provokes the reader to take a stand on both those issues: the philosophical and the sociologi- 
cal one. For the sake of the precision of our exposition, the reader should not get confused by these two domains. Rather, he or she should carefully distinguish between the two so that each may be treated as relatively independent of the other. This is the method adopted in the present text. In the philosophical part (II), we shall mainly consider the problems alluded to by the first phrase in the title of Donati's text: "The Possibility of Humanism After Modernity." With this purpose in mind, we will ponder the meaning of the titular humanism and confront it with post- and transhumanism, both of which are invoked by Donati himself. Referring to Martin Heidegger's famous Letter on "Humanism," we will inquire into the source and justifiability of these distinctions as well as into where Donati's conception is located with reference to the former. Yet before we turn our attention to some general problems of a philosophical nature that Donati's conception poses, we will consider his idea from a purely sociological point of view. First, we will study the possibility of the purely empirical application of the concepts constituting Donati's theory and their methodological effectiveness. Then we will also pose a question regarding the theory's normative aspect.

\section{I}

Let us start with enumerating some difficulties that emerge in approaching Donati's theoretical proposal from a purely sociological standpoint. The following question is definitely valid: to what degree is the theory of relational sociology formulated with the intention of providing an epistemic category that would allow for the better recognition and description of social reality in concreto, and, on the other hand, to what degree is the theory a postulate that assumes a normative position towards reality or even aspires to shape it to some extent? Donati seems to claim that a type of sociology that keeps its distance from any normativity will be unable to provide us with the analytical tools that are indispensable to cognize social reality. The dilemma between cognizance and shaping reality is not thus trivial and is not reducible to the adherence to one or the other set of values. Thus it is worthwhile to take a closer look at it.

In striving for some sort of answer to the above question, it should readily be noticed that in Donati's theory presented here a purely epistemic aspect merges with the normative one.

Donati's thought can be promptly subsumed under humanistic sociology, in opposition to those theoretical tendencies that assume a lesser or 
greater reification of human being. Thus Donati opposes theoretical approaches that describe social reality in ways that, in his view, validate the anti-humanistic mechanisms of modern society. One such conception is, for example, systems theory. It is little wonder, therefore, that in one his first steps, Donati expressly objects to Niklas Luhmann's neo-functionalism, regarding it as a paradigm example of an anti-humanistic epistemic perspective. He confronts it with a sociological theory that involves continuously taking the human person into consideration. In his opinion, the subjectivity of a person is inextricably intertwined with the person's relations with other persons. On the one hand, it is true that a human person, who "comes into existence" only by virtue of the existence of Others and by virtue of relations with them, is never a Self isolated within its own subjectivity and from the world. On the other hand, it does not ensue that these relations thus become a separate entity, detached from given persons, and capable of being represented-as is the case in neo-functional analyses-in complete abstraction from the individuals constituting them. The primordial struggle of humankind to transcend its boundaries (the need for transcendence) is realized in interpersonal relations. Donati consistently emphasizes that people are constituted by their relations with Others, and that through being receptive to another person, we become persons ourselves and that a Subject is inextricably connected with Others. In other words, being in a relation with Others, a Subject creates with them a certain constitutive whole. From a historical point of view there is no doubt that, on the one hand, the so-called modern epoch amplified the process of individuals transcending their limits, simultaneously unleashing ever more possibilities. On the other hand, the said epoch has come, in a sense, to hinder this very process by building increasingly complex social structures, which have somehow started to live their own lives, treating individuals not only as actors but mainly as objects of influence. Therefore, in Donati's opinion, there is a need for such a sociological theory, being humanistic in its message, which would allow for separating the relations being conducive to building a personal subjectivity from those that erode it. This is also the task of the new relational sociology, and the very normative dimension of scholarship, which, according to Donati, no sociology should relinquish for as long as it aspires to keep in close contact with social reality.

Donati's contribution is not solely an exposition of the category of relation-which is after all a ubiquitous category in science and sociology-but also a normative description of the category. In order to even better elucidate the category's theoretical peculiarity, Donati critically as- 
sesses those research perspectives that in recent years shape the landscape of sociological disputes. First, these are the above-mentioned systemic approaches - common in sociology — that favour a third-person perspective, and thus, nolens volens, contribute to the reification of individuals. In the light of these approaches, human being is merely a substratum of the relations generated by large social structures. Putting aside the value of particular individuals and considering their respective relations with others in terms of transpersonal, anonymous, and totalizing social structures contributes to the intensification of the negative (and hence dehumanizing) tendencies of the modern world. Second, Donati mentions those theories that-while being opposed to the above-mentioned dehumanizing approach-merely emphasize the first-person perspective, which consequently favours another negative tendency of the modern world - its extreme individualism and subjectivism. In the light of the latter, humans are isolated beings and their relations with other individuals are simply contingent and instrumental in nature. Criticisms of both systemic thinking and of theories granting primacy to human individuality constitute the negative account of the relational sociology proposed by Donati. At the core of this theory is a thesis on the relationality that constitutes a human person, and this very concept of relationality determines the content of the remaining conceptual categories. Without them, a proper approach to social reality and its creation (morphogenesis) would be impossible.

One of the central categories put forward by Donati is the concept of relational goods, which emphasizes the significance of the relation itself. A relational good not only stems from the relation but can also exclusively be experienced with a person or persons in relation with whom the very relational good emerges. A relational good is indivisible; it is not an aggregate of individual goods and cannot be experienced by a single Subject. Because it is obvious that not every social relation leads to a relational good, the latter has its own counterpart in the form of a relational evil. Through the perspective of "You" and through the experience of a relational good or evil, the category emerges of "We" and of the relation between "Us," and thus the very essence of the existence of a society. In Donati's theory, a person participating in creating and experiencing a relational good obtains in exactly this manner the opportunity to transcend his or her boundaries, that is, such persons transcend themselves. Furthermore, this is what humanism is all about and at the same time experiencing a relative good is a mechanism in which multifarious social forms (structures) transform themselves. The normativity of doing sociology involves creating concep- 
tual categories that allow for checking whether given social relations enable the said transcendence and thus either add to the possibility of the development of humanism or rather stymie it. In other words, everything boils down to the question of whether they strengthen the subjectivity of a person (let him or her flourish) or weaken it. What is more, the question is whether they overcome or perpetuate the negative repercussions of modernity. In Donati's view, sociological theories that keep a distance from normativity conceived of in these terms are unable to recognize the mechanisms by which societies emerge and transform.

The argument formulated above is convincing insofar as a relational good and the emergence of the category "We" stemming therefrom is empirically verifiable. This possibility emerges especially on the microsocial scale, as opposed to macro-social relations, which are much less illuminated. Donati pays far more attention to those micro-social relations. However, it is in the possibility of reconciling micro- and macro-social analyses that a serious misgiving arises. Namely, it is unclear by virtue of what set of concepts the constitutive unity of a person and his or her relations with Others is to be considered in macro-social analyses, which-as is known-are key to doing sociology and to cognizing social reality. In the text under analysis it is difficult to pinpoint any argument demonstrating a shift from reasoning on the micro-social level to higher ones. We will address this weakness shortly; now we should note an important point regarding the analysis of social networks included in this criticism of "relationist" theories.

Extensive critiques of the systemic approaches - usually functionalist - at some point gave rise to the hope that what could be created instead was not a system but a descriptively adequate approach to social reality. The answer was supposed to be the concept of social networks. In this context, it is worthwhile to note Donati's distinction between the relational approach (under which his theory is subsumed itself) and relationist ones (e.g., network theory). As opposed to the former, the latter does not regard human persons (nor their relations with other persons) as equally important shapers of social reality. In relationist approaches, a person is rather conceived of as "made up of social relations" (Donati 2017b: 18). Thus, a human person is again deprived of subjectivity and what is favoured instead is the reification of the person. Relationist theories regard social processes, instead of human persons, as the driving forces generating relations. By contrast, in his relational sociology, Donati underlines the importance of a human person's reflectivity, which must accompany rela- 
tions to endow them with this driving force and at the same time to enable individuals to transcend themselves (and their respective limits). From this vantage point, it is worth noting Donati's critique of the inadequacies of constructivism. As opposed to constructivism, relational sociology, in its quest for conceptual categories that would allow for pinpointing and describing real constraints in constructing social reality, assumes, on the one hand, a person's reflective relationality (anchored in morality, among other things), and on the other hand, the inevitability of an external reference to a "transcendental cultural matrix."

This last category, which-apart from a relational good-seems to be one of the most important concepts in Donati's theory, gives rise to serious doubts. The murky status of the "transcendental cultural matrix" is an obstacle to finding a connection between the micro- and the macrosocial level. Moreover, interpretation of the text is not facilitated by a certain confusion between the meaning of transcendence and transcendentality (which will be more extensively addressed in the second part of this article). In Donati's text, there is no single, consistently applied concept with a clear meaning; instead, we find a whole array of derivative expressions whose meaning is - as we can guess - synonymous or nearly synonymous. Thus we encounter, for instance, "cultural matrix," "symbolic code," "transcendent symbolic matrix," "transcendental matrix," "transcendental principle," "transcendental sense," and even "transcendental reality" and "transcendental realities." At the beginning of his exposition, Donati states that "By 'transcendental matrix' I do not mean the dogmatic beliefs of a specific religious faith, but the symbolic code underlying every great culture or civilization concerned with ultimate realities. It is a matter of fact that any science does refer to some kind of transcendental matrix, although very often in an unwitting or unspoken way" (Donati 2017b: 10). This expression would be fully satisfactory if it were applied in successive parts of the text consistently. Indeed, Donati does rightly require sociological theories clearly to specify which "cultural code" they refer to while constructing their analytical tools. However, in apposition to the expression referred to, instead of some explanation, what we get is another category, whose meaning we can only conjecture: "All sociologies have a cultural matrix that depends on a 'mother-matrix' where ultimate realities are placed"'(Donati 2017b: 10). Quite as before, the status of this "mother-matrix" is unclear. The procession of vagueness goes even further: "The recognition of the dignity of every entity (in Latin the word dignus means 'a thing or a person deserving respect for its qualities') marks 
the boundary between what I call 'immanent transcendence' (as a product of society) and 'transcendent transcendence' (as a reality which is not the product of society)" (Donati 2017b: 11). So what appears—and now continues to accompany the reader-is a dual doubt. First, is the category of "cultural matrix," and concepts akin to it, created by people (or society), or is this "transcendental reality" supposed to describe something to which people have only limited access and therefore cannot influence? Second of all, does "cultural matrix" refer to a real entity or is it rather an epistemic category specifying a research perspective adopted in a given sociological theory. These doubts continue to haunt the reader throughout the text. The following explanatory note is also of little help: "In summary, the problem is the following: whether or not it is necessary-if not, why, and if so, what is it - to have a symbolic matrix that allows us to face the enigma of the relation in such a way that it is possible to see how and why human relations and transcendental relations are ontologically connected to each other" (Donati 2017b: 11). Furthermore, the "enigma of the relation" permeates the entire text not so much as a strictly sociological category but as a signal that the author means something that is barely expressible in words, at least within scholarly discourse, or the realm of philosophy-something that could most readily be explained in poetry. Still, Donati attempts an explanation by introducing another conceptual category, that is the concept of "vital relations," which in turn makes reference to another obscure expression, that is, to the "transcendental order of reality." Donati writes:

What brings together the first and second causes is what I call the "vital relation," which is both human and social (i.e., which relates the human and the social to each other) by appealing to a transcendental order of reality. It "stands outside" of terms that it gathers, with its own qualities and causal powers. The vital relation is the relationship outside a human person that is necessary to herself in order to be reflexive in herself on herself, so that she can tell herself to be herself, on the basis of distinctions with what is not (Donati 2017b: 19-20).

The fact that Donati's text does not fully elucidate the concept of "cultural matrix" causes the text to lack a proper point of departure to construct successive sociological concepts, which would, on the one hand, take into consideration Donati's determinations in the sphere of the essence of the human person and sociological micro-relations, and on the other hand, would describe phenomena on a macro-sociological level, which are-after all-largely responsible for the dehumanizing tendencies present in our modern world. Such a missing link could be, for example, social 
institutions which, although they constitute "matrices of sense" independent of individual actors, are continuously negotiated in dozens of social relations and are ultimately transformed as more social experience accrues. We construe the incompleteness of such concepts as "transcendental cultural/symbolic matrix" and "vital relations" as an implicit belief that the relations between people cannot be treated as a being per se-to which, incidentally, Donati strongly objects and which is the reason for his sharp criticism of approaches reifying the human person. As convincing as this last thought may be, the emphasis put upon the "transcendental" nature of such entities as "transcendental order of reality" has its cost, which consists in losing the possibility of creating constructs that would be sociologically clear, that is, empirically verifiable. A relevant example is the view of a relational good that would allow us to describe social relations in empirical terms, simultaneously making explicit references to the macro-sociological level and endorsing relational analyses of larger social forms/structures without diminishing the sense of subjectivity of the human person. In another lecture, ${ }^{2}$ Donati demonstrates the role of large social forms when it comes to creating various kinds of opportunities. These relations between macro and micro levels and the study thereof are nothing new in sociology as such. Yet, in relational sociology what would be meant thereby is something else: having adopted Donati's conception of the human person and the role that relations play therein, sociological conceptual categories could be produced that would reveal the mechanisms of subjectively transforming macro-social structures. A concept of cultural matrices could thus be constructed (but not transcendental ones, which are conceived of unequivocally as the product of people, while being at the same time transformed by people themselves). However, what would also be at stake is a wide of array of other concepts referring to different levels of organizing social life and its various aspects. The above-mentioned social institutions, coupled with their formal and informal aspects, would be proper examples here. These sorts of concepts could be useful in studying the mechanisms of social change and the transformations of large social forms in which people, on the one hand, experience significant constraints in constructing social reality — as was rightly underlined by Donati himself — and on the other hand, have some room for subjectively transcending their limits. To regard

\footnotetext{
2 The text "Human Fulfillment in a Morphogenic Society: Challenges and Opportunities from a Relational Standpoint" presented at the seminar "Humanism in an After-Modern Society: The Relational Perspective," University of Warsaw, March 6, 2017 is an enlarged version of What Does a 'Good Life' Mean in a Morphogenic Society? The Viempoint of Relational Sociology, by Pierpaolo Donati in: Margaret S. Archer (ed.), Morphogenesis and Human Flourishing, Springer, 2017.
} 
such categories as the business enterprise, the association, or even the state as social networks does not seem sufficient to grasp their dynamics while taking into account the subjective role of the actors entangled in them. Resorting to the constitutive role of "social molecules" (Donati 2017b: 23) is important, but this is not a concept that would illuminate the mechanisms connecting micro- and macro-social dynamisms. In the present variation of the text, what emerges is perhaps an unintended impression that the subjectivity of a person is mainly or exclusively realized in micro-social relations, that is, on the basis of personalized relations (e.g., "significant others"), and when we abstract from these, what remains for a person is the resort to an underspecified "transcendental reality" situated somehow beyond social control.

In the final parts of the text, Donati poses the question, "When can a social form be called human?" (Donati 2017b: 22). It is exactly at this moment that what could be offered are the sociological concepts with which the macro-social part of relational sociology is more conspicuously furnished. Instead, what we encounter is another vital statement returning us to the question posed at the beginning of this part of our text, that is, to what extent does relational sociology provide us with epistemic categories applicable to studying reality, and to what extent is relational sociology formulated from the position of a desired end-state and thus becomes a postulate itself? As we stated above, epistemic and normative threads are indistinguishably blended there. It can be conjectured that this manoeuvre is deliberate and is aimed at overcoming those consequences of modernization that should be evaluated—on the grounds of a rational theory—as evil or harmful, which means dehumanizing and eroding social relations. Donati formulates a sort of credo:

The most hidden reality of human life can mature as such only if it passes through appropriate social forms, that is, relationally valid to generate and express the humus of the human flourish, that is, the relationality of the good life. A social formation can be called human to the extent that the nature of its internal as well as external relationality is qualified by the recognition and satisfaction of basic human needs and nourishes people's reflexivity in order to help them to realize their ethical ultimate concerns as a way of transcending human limitations (Donati 2017b: 22). 
As we already mentioned, according to Donati, in constructing theories sociology should pay attention to whether the analytical tools the theory provides allow us "to read the signs of the new historical dynamics" (Donati 2017b: 15). Donati constructs his theory while exposing the importance of relations for the constitution of human persons because that is the way he construes "basic human needs," and in particular the need to realize the "ethical ultimate concerns" by which a person is driven. Such an interpretation of social reality entitles him to place his sociological theory above the need to make evaluative judgments as to which social structure is good and which is bad. He labels his theory a "concrete utopia," that is, one that is empirically grounded, as opposed to the "abstract utopias" that are sometimes formulated. This "concrete utopia" probably aspires to change the world, and what it definitely aspires to do is to recover the social bonds that are the essence of a human being. For this goal to be attained, some analytical categories are needed-the categories making researchers sensitive to the needs cherished by people, including ethical needs.

\section{II}

The doubts that Donati's theoretical proposal raises from a purely sociological standpoint are augmented when its philosophical and cultural context is taken into consideration. We shall now try to supplement the problems of a strictly sociological nature presented above with critical reflections on Donati's proposal, while bearing in mind its broad context, which according to Donati himself should be remembered in assessing its truth and propriety. On our part, it is not an act of usurpation at all that we situate a given proposal for a sociological theory in such a broad background. Donati himself claims that this should be the case. The very title of his text- "The Possibility of Humanism After Modernity"-leaves us with no delusions as to what is at stake here. In the light of the above remarks, it seems quite justified to maintain that Donati's theory does not constitute such a radical turning point in sociology as it would be if it were willing to live up to its own revolutionary declarations and make a breakthrough in thinking about human and society.

What serves as a common denominator of the first and the second part is a remark Donati recalls about thinking in terms of utopia and the significance of the category of "opportunities." From the historical point of view, it is obvious that both the category of "utopia" and the accompanying category of "opportunities" are very deeply anchored in the way of 
thinking representative of the modern age. Whereas in medieval thought, it was rather "necessity" that was the category of existence that determined people's view of themselves and the world, with the rise of the modern age it was the category of "possibility" that gained the advantage. The latter category perfectly corresponds with the other categories typical of modernity: with the concept of novelty, liberty, subjectivity, creativeness, labour, development, imagination, etc. From Donati's proposal, it can be inferred that in the postulated epoch of "after-modernity," people should still move within a wide range of options but should pay more attention to their subjectivity, the basis of which is interpersonal relations. However, this implies that what we are dealing with here is a sort of paradox which involves overcoming the negative consequences-in Donati's estimation-of the Enlightenment paradigm, on the grounds of this very paradigm. Can an attempt be made to replace the negative consequences of certain tendencies of modernity by its positive attributes? Or, to the contrary, is it not the case that in repudiating the negative tendencies of modernity, the same must unfortunately be done to the positive ones because both constitute two sides of the same coin? How can a solution be found to the dilemmas of the contemporary world (modern, postmodern, and after-modern) by relying on the same model of understanding humanity that, on the one hand, offered subjectivity to the individual, and, on the other hand, caused this very subjectivity to be more and more threatened?

Donati's general strategy of combining strictly sociological considerations with a philosophical approach should come as no surprise. All revolutions - irrespective of whether they pertain to science, politics, economics, social life, religion, or the arts-are always realized on a borderline, where a given discipline borders the philosophical reflections corresponding to it, and these philosophical reflections set the so-called conceptual primes of the discipline. The said primary concepts frame something resembling a Kuhnian paradigm. At this point, Donati speaks of a transcendental pattern (matrix), which as a cultural code delineates the ways human persons cognize their environment and themselves. This code shapes a given representation of the world. From the viewpoint of philosophy, it can be said that these concepts specify certain characteristic modes of the existence of things, with which the said disciplines deal. Due to the conceptual primes, a given discipline is assured a reference to a given stretch of the world which that discipline "appropriates." For a revolution to take place, even the most spectacular idea, plan, or discovery in a given field will prove insufficient as long it does not give rise-through philosophical investiga- 
tions - to a redefinition of primary concepts. However, the change in the content of those concepts is very difficult because they have a multi-layered structure and come from a historical stock of meanings which, as history proceeds, settles how the mode of existence of a given domain is understood. Revolution does not just involve attaching a new layer of sense to the existing ones, but rather their destruction or deconstruction. The latter is about questioning, unleashing, and making variations on the existing senses. Thus if determinations in a given domain are to be revolutionary in nature, the domain's primary concepts must be called in question. This usually materializes in a two-fold manner: "bottom-up" or "top-down." A bottom-up revolution takes place when some discovery or change in historical reality induces us to pose new philosophical questions; a top-down revolution, on the other hand, takes place when, anticipating some turmoil in the abyss of Being, philosophy opens up previously unknown horizons wherein things acquire surprising new facets. And it is precisely these that are grasped by scientists or people of action in making major discoveries or, respectively, introducing spectacular changes to reality.

Going to back to Donati, who in his new theory strives for the highest goals of both a theoretical and a practical nature, it must be said that a revolution in sociology and a fortiori in the realm of social life can materialize only when empirical and purely theoretical investigations are accompanied ante aut post with intense philosophical reflection concerning such primary concepts as human being, society, interpersonal relations, personhood, happiness, liberty, value, culture, etc.

And indeed, this is where the great value of Donati's work lies-that in wanting to present his idea about a new approach to sociological issues, Donati does not evade taking up philosophical motives or investigations. However, it is exactly this realm of reflections-as can easily be guessed-where the biggest dangers threatening the entirety of his conception loom.

Let us start by reminding our readers of the general philosophical and cultural background against which Donati launches his reflections. What is meant is humanism and the latest attempts to overcome it, that is, post- and transhumanism: in the face of all the variations upon "the death of man" and the belief that humankind is weak, frail, and imperfect, humankind struggles - by developing high-tech technologies - to transcend its limits and create a new species of human-a trans- or superhuman. This idea is called transhumanism; in the last decades of the twentieth century, it resonated among philosophers, scientists, politicians, and pop-culture artists. 
Sometimes, while enumerating the sources of inspiration for such a view of the human person and its transformation, Nietzsche's thought is adduced. Enlightenment sources - in which individuals, freed from God's help and violence, must single-handedly transcend their limits to attain on Earth what was earlier expected only in heaven-are also indicated. The perfectly full array of human possibilities and happiness remains the ultimate end here and in heaven alike-what changes are only the means of reaching it. Salvation through grace is thus replaced by human self-perfection armed with reason and technological means, with humans owing whatever they have to God or to the evolution of their own cunning and skill. The epoch in which humankind gradually becomes aware of its own autonomy and creative potential is called modernity (the peak is the Enlightenment period). As the name suggests, it is a time of looking forward and creating what is new. The future, creativity, liberty, the transcendence of boundaries, modernity, labour, imagination-these are only some of the categories that might be used to describe this turbulent epoch. The strenuous and irrepressible struggle for something that is not out there yet but that seems, from today and tomorrow's viewpoint, better and more efficient finally makes the very impulse to struggle itself into a constraining factor that must be overcome. Revolution eats its children. Modernism becomes a burden and a limitation, from which it must free itself. Humankind must step further and transcend modernism, because going back is not feasible and the call to transcend and move forward is principally modernist in nature-what one is left with is a sort of trans-modernism, postmodernism, or finally after-modernism. In each case, the call to transcend human limits remains in effect. Human being is something that shall be overcome (Nietzsche).

In his short exposition of the philosophical and cultural background, Donati seems to miss one crucial thing. He does not properly and consistently distinguish between what is referred to as transhumanism and what is labelled post-humanism. This is indubitably not merely a verbal problem, although it is the case that both names often function as synonyms. However, attention should be drawn to the essential substantive difference between the two. It is certainly possible, without much qualification, to approve of what Donati understands by transhumanism or post-humanism. However, in adopting such an approach, we would miss something of importance, something that does not allow us to fully appreciate the position of Donati himself. What Donati calls post-humanism is still subsumed under a broadly construed transhumanism—as he concedes himself, after 
all. From this perspective, his own position seems to him to be radically different. Still, from the position of properly understood post-humanism (which we shall scrutinize shortly) even his position should be classified as transhumanism. In regard to the difference between transhumanism and post-humanism, we posit that we are confronted with two radically different ways of understanding humankind and reality.

The idea of transhumanism is relatively well known and there is little point in elaborating upon it any further. Let us just say that although the idea seems to be relatively new, its understanding of humankind is derived from the ancient description of human being's essence as a rational animal.

Throughout history, human person's essence, thus understood, was explained in manifold ways: human being is an animal, which is and wants to be more than a mere animal; they are a combination of body and soul, a combination of what is earthly and divine; the are the only entity deprived of any lasting and ready-made essence; they are a being-in-itself and a being-for-itself; they are what they are not or are not what they are; they are an existence which precedes essence, etc. Due to his ambivalent nature, human being incessantly struggles for something, is an open being transcending itself, stepping out of itself; they are a being in transition, in movement, in the process of change. The consequence of this dynamic human nature is history and technological progress. The latter allows human being to transform not only his environment but also his body, which, when combined with new technologies, gradually overcomes its natural limitations. By dint of new materials and technologies, human person is able to lastingly and organically connect his body with instruments. The ultimate goal is to connect his body-especially his brain—with a machine (a computer or virtual reality) in such a way as to provide him with full transcendence and allow him to become an almighty god (Adamski 2012; Ilnicki 2011).

Due to the above, it can be said with a small hint of exaggeration that any humanism somehow entails transhumanism ex hypothesi. Because human being is what permanently transcends itself, reflecting upon and protecting its nature-which is what is normally referred to as humanism-human being must be ceaselessly renewed and transcended. Hence, humanism as trans- and neo-humanism is strictly related with metaphysics, which-by analogy to human being's self-understanding-is founded upon the idea of transcending (meta) any being (physis) by what is called its basis, condition, ultimate cause, and what is associated with some primordial principle (arche) or with God, etc. 
Confusing transhumanism with post-humanism is a misunderstanding because the latter constitutes a critique of the fundamental philosophical principles of the former-or more broadly, of humanism as such and of the metaphysics connected with it. Whereas transhumanism is an attempt to infer ultimate positive consequences from the above-mentioned understanding of human being, as well as being an attempt to "ultimately think over" the traditional European metaphysical conception of human person, post-humanism is an attempt to deconstruct the former, to overcome it (Überwindung) — not, however, in the sense of transcending and "going further," which would render it much like transhumanism and humanism, but rather in the sense of twisting it (Verwindung). The philosophical assumptions of post-humanism were provided by the philosophy of Martin Heidegger. Its ideological successors mainly belong to metaphysics elaborated from the position of phenomenology (this metaphysics found its most creative representatives in France in the twentieth century). To learn what posthumanism is, it is best to study Heidegger's famous Letter on "Humanism," in which - without specifying his own position towards post-humanismthe author presents the ideas representative of this intellectual formation. The fact that neither Heidegger nor the adherents of Heidegger's approach explicitly call their positions post-humanism is not an act of negligence on their part; it is rather a deliberate strategy aimed at emphasizing their radically different position towards transhumanism and humanism, and hence towards metaphysics as such, which, as is well known, relishes the creation of new "isms." However, because their thought to a large extent concerns humankind, whose nature is at stake in this philosophical-historical battle and is therefore principally of a humanistic, rather than naturalistic or theological, nature, it can be labelled "humanistic" or post-humanistic reflection, which means that it not only studies humankind as such but also cares about humankind (and its humanitas) as such. What is its main message?

The point of departure is the thought that "any humanism is based on metaphysics or else it makes itself a basis of metaphysics"(Heidegger 2004: 321, transl. M.F., D.S.). ${ }^{3}$ Metaphysics here is construed broadly as a reflection on the essence of Being and embraces ontology, a discipline which is usually distinct from it. The idea of humanism being founded upon metaphysics expresses in other words the same contention as the one we signalled at the very beginning of our considerations while speaking about the connection between different domains of reality and philosophy's de-

\footnotetext{
3 In the original text: ,Jeder Humanismus gründet entweder in einer Metaphysik oder er macht sich selbst zum Grund einer solchen.”
} 
scription thereof (primary concepts). In this connection, Donati speaks of a transcendental pattern. Human being and the human community can not be pondered without raising, nolens volens, metaphysical issues. Especially at present, when the essence of human person is associated with things, and when he or she is treated as one of those things (transhumanism, actor-network theory etc.), what is required is a deeper reflection upon human person and other beings. On making some preliminary determinations in this field, it is visible - says Heidegger - that "the highest determinations of the essence of the human being in humanism still do not realize the proper dignity of the human being" (ibid.: 330). ${ }^{4}$ And this is the case because they are clearly alien to the explicitly posed question about Being (Sein). Metaphysics asks only about what is out there (the things in existence) (Seindes), and so about these or those things, and is not concerned with questions that attempt to get to the sense and truth of Being itself. Because it does not ask about Being, it unwittingly treats Being as a lasting substance, or as presence (Anwesenheit, Gegenwärtigkeit, Vorbandenheit), and as the highest cause and foundation. From the perspective of existence thus conceived (Seindes), which — as metaphysics — creates the history of European culture, what is determined is the leading understanding of human being as animal rationale and particular modes of human existence. In Nietzsche's thought, which laid the ideological foundation for contemporary times, this sort of thinking reaches its final stage, after which either the same pattern will recur ad inifinitum - which is referred to as technological, civilizational, and social, etc., advancement-or a change in the social order will come from the middle of nowhere. In Heidegger's opinion, man understood from the perspective of metaphysics is unable fully to be what he is because the said understanding of man casts a shadow on his proper essence, which lies in his existence, connected with the clearing (Lichtung) of Seindes. Still, this way of thinking cannot be modified just like that, without any reflection upon the basic thread of metaphysics, which is existence and its history. Hence the humanitas proper to man can only be specified and man's dignity protected when it becomes possible to overcome the metaphysics-derived conception of existence as a lasting presence. Not only the understanding of man as an animal rationale ensues from this conception, but also everything else connected therewith: the concept of liberty, ethics, value, subjectivity, community, family, state, society, instruments, technique, God, science, and art. This overcoming will not, however, materialize through

4 In the original text: „Vielmehr ist der einzige Gedanke der, dass die höchsten humanistischen Bestimmungen des Wesen des Menschen die eigentliche Würde des Menschen noch nicht erfahren.” 
the creation of new philosophical systems or scientific theories- this sort of theoretical attention is a way of thinking that is entangled in the categories of presence.

How does Donati's idea of relational sociology look from this post-humanistic perspective? How does Donati conceive of humankind as such? Donati here invokes the nature of humankind as being unique relative to the rest of being, and lying in its intersubjective relations. That is why, in his opinion, it is erroneous both to conceive of humankind as a derivative of relations and system (the third-person perspective) and as subjectivity closed within itself (the first-person perspective). To approach the nature of humankind properly, a second-person perspective should rather be invoked. Forming a relation with "You," a human person creates relational values (good and evil), which intensify the dynamism of his or her growth qua person. Humankind is after all an entity that permanently transcends itself, from what is toward what can be, between being and non-beingand it does this best in interpersonal relations. This understanding of humankind is founded upon the traditional metaphysical thesis that

at the beginning (of any creation, not only of the original creation) there is not a bottomless depth, but a Being ever able to transcend itself by relating himself to the Non-Being. It is in this process of transcendence (emergence) that being and non-being are related, while no one of them can exist per se in absolute isolation. The very nature of creation would then consist in a relation that brings into existence what does not exist through a process of emergence (Donati 2017b: 9).

The general assumption is that substances and relations are principles of social life that are of equivalent importance. Construing human being as a relational entity, as suggested by Donati (internally, this is a bodysoul relation, whereas externally, it is human person-environment), with this entity emerging in the creative process of transcendence from being to non-being, is - contrary to its revolutionary aspirations - unfortunately yet another form of metaphysical thinking of human being as animal rationale, that is, as an entity which transcends (and it must do so) its existence towards what is not but could be out there. And the question whether the above is endorsed by being-in-a-relation towards other people or creating relational goods, or by something else, is of merely secondary importance. The way Donati understands the very concept of transcendence as a meta- 
level of reality is indubitably entangled in a metaphysical-theological framework of thinking. Apart from that, two more things seem to raise doubts.

First, Donati does not seem to distinguish what is transcendent from what is transcendental. And these constitute two radically different categories, whose confusion should be avoided at any cost. The modern distinction between the two was formulated by Kant himself. In medieval thought, a transcendental character was assigned to what we somehow always presuppose whenever we think of something existing: be it ens, res, unum, verum, or bonus. In Kant's thought, "the transcendental" also refers to something which is conceptually prior (prius) to our epistemic grasp of objects. Yet Kant narrows his investigation to the understanding of objects that is possible a priori (pure natural science or mathematics). What are studied in transcendental cognition are the necessary essential concepts and ideas of pure reason, by virtue of which the prior-to-experience world of objects and the knowledge thereof are constituted. By contrast, the concept of "transcendent" refers to beings that lie beyond the capacity of our experience (such as God, the soul, or the beginning of the universe). In other words, what is "transcendental" is cognition or understanding and what is prior to and constitutes our conceptualization of the world of objects; what is transcendent, on the other hand, are objects: objects of our perception as related to that very perception or such being that lies outside the capacity of any cognizance (Kant 1974: 63; Höffe 1994: 47ff.).

Second, while remaining true to the metaphysical perspective, Donati does not reach any ground-breaking conclusions. Does not the thesis that human being is and becomes human person only in relations to other people-to which relations, human being is, however, not reducible-seem utterly trivial from the viewpoint of social philosophy? Does the other thesis not permeate the entire edifice of social theology — the thesis positing that for a person to become a person in relation to other people, he or she needs to refer to a transcendent being (God?), which endows these relations with a hint of something "necessary" and "good"? Does that mean that the mystery of a relation to other people and to God consists in its relationality? The contention that "at the beginning there was a relation" and that human being is a relational entity presupposes some ontology, and further, metaphysics of relation.

It is known that thinking in terms of relations is very old, derived from as early a thinker as Plato himself; it is the framework that was theologically supported in Judeo-Christian tradition, and it became a primary ontological category together with neo-Kantism and the philosophy of science. 
In Heidegger's thought as well, the concept plays a vital role. After all, he points out that man as Dasein is essentially a being-towards, which assumes different forms, such as, say, being-in-the-world, being-towards-death and also being-with-others and being-others-related. So if sociology is assumed to be the science of studying different forms of being together (Mitsein), to speak of "relational sociology" is as pleonastic as it is vacuous. Heidegger says that "Relation is a formal definition which can be directly read off by way of 'formalization' from every kind of context, whatever its subject matter or way of being" (Heidegger 2004: 77, par. 17). ${ }^{5}$ Hence there is a need for further specification. If such a specification is missing in speaking of a relation, what is being spoken about is virtually everything and nothing.

Due to the above, Donati's call for the redefinition of primary concepts (the transcendental matrix) in such a way that they should serve to better elucidate and build social relations seems, albeit justifiable, impossible to realize while sticking to the traditional metaphysical framework. We concur with Donati that personal relations are full of paradoxes and that is why one must learn to think paradoxically, but it is not possible from the word "go." Donati's project fits a certain tradition of "humanistic" thinking which was common in the twentieth century and which, based on a negative assessment of contemporary times (untamed technological advancements, the virtualization of reality, vanishing interpersonal relations, etc.), tries to search for a solution by re-establishing intentionally or not-certain ideas representative of Christian culture. Then, one readily starts to refer to such ideas as caring about people, the ecology, humanism, neo-humanism, etc. without realizing that the suggested solution actually belongs to the same movement (the metaphysics of presence) that one is apparently opposing.

\section{/// Conclusion}

There is no doubt that Donati's theoretical proposal constitutes an important point on the map of contemporary sociological disputes. The call for humans to recover their well-deserved dignity, coupled with an emphasis on the value of interpersonal relations, necessarily arouses respect and approval in modern society, which is after all inclined toward collectivism and individualism. There is a need for a middle-of-the-road position that

\footnotetext{
5 In the original text: „Beziehung ist eine formale Bestimmung, die auf dem Wege der 'Formalisierung' an jeder Art von Zusammenhängen jeglicher Sachhaltigkeit und Seinsweise direkt ablesbar wird."
} 
would overcome the difficulties of systemic thinking on the one hand, and on the other, extreme anarchy-like individualism and relativism. The theoretical and world-view-related foundations of both these positions were formed at the turn of modernity, and that is why what is true is that by questioning modernity's leading paradigms and transcending them, it will be possible - both from the theoretical and practical point of viewto remedy modern society. The question remains open: can this be done by dint of one loud, ground-breaking move or is what is needed rather a revolution by small steps and at a slow pace, after which what is true will remain. Judging both from the substantive perspective and on the basis of the sort of optimistic mood which usually accompanies its announcement, it seems that Donati's proposal rather inclines to the former option. However, in postulating the necessity of overcoming limitations, stepping beyond them and transcending them, creating utopias, building new roads for development, searching for new opportunities, etc., Donati's proposal thereby confirms that it is a true successor of modernity, and thus a hostage to both its positive and negative philosophical, world-view-related, and cultural assumptions.

Revolutions in sociology take place when advanced empirical investigations are accompanied with intense philosophical reflection, with the latter being courageous enough to be confronted with the most important ideas of the European tradition. In other words, relational sociology should be supplemented with a greater awareness of theoretical and historical interdependencies. For example, in the case of relational sociology, the most important idea is relation. If one contends that it is exactly this category that can overcome the limitations of contemporary intellectual and cultural formations, one should embark upon its historical (de)construction, that is, one should unravel its hidden senses, which have accrued throughout history, and confront them with the "thing itself." In the process of deconstruction two scenarios are possible: it will either transpire that the original intuition of the concept is right on the mark and that actually, after investigation, this very concept, freed from metaphysical connotations, will turn out to be useful in building a new paradigm for considering humankind and its environment, or else the investigation will demonstrate that the concept is so strictly and inextricably connected with the most fundamental metaphysical categories that using it to build a new research perspective will be impossible without resort to other concepts representative of metaphysics - and these concepts are no longer (or perhaps never were) compatible not only with a bygone epoch and its primary metaphysi- 
cal experience but, first and foremost, with the metaphysical requirements of contemporary times. There is some fear that in-depth investigations into the history of the notion of relation will make the second scenario more likely.

Bibliography:

/// Adamski K. 2012. Transhumanizm. Między utopia, biotechnologia i gnozq, "Roczniki Teologii Moralnej", vol. 4(59), pp. 105-129.

/// Donati P. [to be published in 2018]. Transcending the Human: Why, Where, and How?, [in:] Ex Machina: Realist Responses to Posthuman Society, eds. I. Al-Amoudi, J. Morgan, Routledge.

/// Donati P. 2017a. What Does a 'Good Life' Mean in a Morphogenic Society? The Viewpoint of Relational Sociology, [in:] Morphogenesis and Human Flourishing, ed. M.S. Archer, Springer, pp. 137-161.

/// Donati P. 2017b. Humanism in an After-Modern Society: The Relational Perspective, unpublished manuscript of the seminar lecture delivered at the University of Warsaw, March 6, 2017.

/// Heidegger M. 2004. Wegmarken, Vittorio Klostermann Verlag.

/// Heidegger M. 2006. Sein und Zeit, Max Niemeyer Verlag.

/// Höffe O. 1994. Immanuel Kant, transl. M. Farrier, State University of New York Press.

/// Ilnicki R. 2011. Bóg cyborgów. Technika i transcendencja, Wydawnictwo Naukowe Uniwersytetu im. Adama Mickiewicza.

/// Kant I. 1974. Kritik der reinen Vernunft, ed. W. Weischedel, Suhrkamp.

/// Michał Federowicz_ - associate professor of sociology at the Institute of Philosophy and Sociology of the Polish Academy of Sciences. His research interests centre around economic change in the post-communist countries, including institutional change; his most recent works are devoted to the role of education in contemporary society.

E-mail: michal.federowicz@gmail.com 
/// Daniel Roland Sobota - assistant professor of philosophy at the Institute of Philosophy and Sociology of the Polish Academy of Sciences. His main areas of interest are German philosophy in nineteenth and twentieth centuries (especially phenomenology and Martin Heidegger's philosophy), and philosophy of question (sensu largo). Recently he published a book about the birth of the phenomenological movement at the turn of the nineteenth century.

E-mail: dsobota@ifispan.waw.pl 
